\title{
Ultrasonographic measurement of placental thickness and its correlation with estimated fetal weight
}

\author{
Nasreen Noor ${ }^{1 *}$, Akanksha Jain', Shazia Parveen ${ }^{1}$, Syed Manazir Ali² \\ ${ }^{1}$ Department of Obstetrics and Gynecology, ${ }^{2}$ Department of Pedriatics, J.N.M.C.H., A.M.U., Aligarh, Uttar Pradesh, \\ India
}

Received: 24 October 2017

Accepted: 17 November 2017

*Correspondence:

Dr. Nasreen Noor,

E-mail: nasreen_71@rediffmail.com

Copyright: (c) the author(s), publisher and licensee Medip Academy. This is an open-access article distributed under the terms of the Creative Commons Attribution Non-Commercial License, which permits unrestricted non-commercial use, distribution, and reproduction in any medium, provided the original work is properly cited.

\begin{abstract}
Background: The human placenta develops with the principal function of providing nutrients and oxygen to the fetus. Objective of present study was to assess the relationship between placental thickness with estimated fetal weight.

Methods: The present study was a prospective observational study and includes 152 pregnant women with known last menstrual period, history of regular menstruation, singleton pregnancy and aged between 20 and 35 years. After Institutional Ethics Committee approval all recruited women were observed for baseline demographic and obstetric data including age, parity and past medical events at first antenatal visit. All women provided an informed written consent and underwent ultrasound evaluation of placental thickness at 18 to 40 weeks of gestation.

Results: In the present study the mean placental thickness between the ranges of $18-40 \mathrm{~mm}$ was $31.63 \pm 4.79 \mathrm{~mm}$ and the mean estimated fetal birth weight was $2145.86 \pm 121.24$ grams. The pearson's correlation coefficient between the two was 0.982 . Thus, proving the significant positive correlation between placental thickness and estimated fetal birth weight (p-value $<0.001)$.

Conclusions: Estimated fetal weight is a very important component of antenatal care in which ultrasonography plays an important role. Placental thickness measured at the level of umblical cord insertion can be used as an accurate sonographic indicator in the assessment of fetal weight because of its linear correlation. Therefore, it can be used as an additional sonographic tool in assessing fetal weight.
\end{abstract}

Keywords: Estimated fetal weight, Placental thickness, Umblical cord insertion

\section{INTRODUCTION}

The human placenta develops with the principal function of providing nutrients and oxygen to the fetus. ${ }^{1}$ Adequate fetal growth and subsequent normal birth weight depends on the efficient delivery of nutrients from the mother to the fetus via normally functioning utero- placental organ. ${ }^{2}$ It is clear that normal development of placenta during gestation is necessary for supporting of a healthy fetus. ${ }^{3}$ On the other hand, any impairment in its development may have a profound impact on fetal development and pregnancy outcome.

Fetal weight estimates are very important because a large proportion of perinatal mortality is related to birthweight. Thus, birth-weight is the single most important parameter that determines neonatal survival.

Obstetric ultrasonography offers the tools to estimate fetal weight and assess placental size. 
Placental thickness is the easiest placental dimension to measure, yet little is known about the "normal" placental thickness as measured by sonography. Historically, a placenta of greater than $4 \mathrm{~cm}$ in thickness has been regarded as abnormal and associated with various poor outcomes. ${ }^{4-6}$ However, the ratio of the birth weight to the placental weight has been used since the 1940s as an index for the appropriateness of fetal growth and there are no current data to support this cutoff value or specifically addressing placental thickness in all trimesters of gestation. As such, few studies have been done to correlate placental thickness with the fetal weight. Thus, the aim of this study is to determine the normal sonographically measured placental thickness in millimeters from 18 weeks onwards and to determine whether this measurement should be correlated with the estimated fetal weight.

\section{METHODS}

The present study was a prospective observational study and was conducted in the Department of Obstetrics and Gynaecology in collaboration with the Department of Paediatrics, J.N.M.C.H., A.M.U., Aligarh. A total of 152 pregnant women aged between 20 and 35 years presented at our antenatal clinic were enrolled in this study from 2014 to 2016. All patients provided an informed written consent after they were fully instructed about the investigation. The study was approved by Institutional Ethics Committee All recruited women were observed at the $1^{\text {st }}$ trimester screening at antenatal clinic and assessed for baseline demographic and obstetric data including age, parity and past medical events. At second and third trimester (18 - 28 and 29 - 40 weeks of gestation respectively), the period of gestational age by last menstrual period.All pregnant women underwent ultrasound evaluation of placental thickness at 18 to 40 weeks of gestation.

\section{Inclusion criteria}

- Singleton pregnancy

- Gestational age from 18 - 40wks

- Known last menstrual period.

- A history of regular menstruation

\section{Exclusion criteria}

a. Gestational Hypertension

b. Diabetes mellitus.

c. Intrauterine growth restriction

d. Hydrops fetalis

e. Congenital malformations

f. Twins.

g. Polyhydramnios

- Last menstrual period not known

- Irregular menstrual period.

- Abnormal Placenta and poor visualization of placenta.
- Placentas with variations in insertions of umbilical cord.

\section{The sonographic technique of placental thickness measurement}

The patient was scanned with a moderately distended bladder in supine position. The transducer was placed on the skin surface after applying the couple agent. The placental thickness in mm was measured at the level of cord insertion site. The transducer was oriented to scan perpendicular to both the chorionic and basal plates as tangential scan will distort the measurement of the thickness of the placenta. The identification of the cord insertion site is vitally important for obtaining correct measurements. The site is usually central but slightly eccentric position may be normal. The ultrasonic appearance of the cord insertion appears either as hypoechoic areas closest to the chorionic plate in the thickest portion of the placenta with a $\mathrm{v}$ shape or as linear echoes emanating at right angles from the placental surface. Placental thickness was calculated from the echogenic chorionic plate to placental myometrial interface near the mid-placental portion. The myometrium and subplacental veins was excluded in the measurements. All placental measurements were taken during the relaxed phase of the uterus as contractions can spuriously increase the placental thickness. The thickness increases during contraction due to distension of intervillous spaces by maternal blood. The length and surface of placenta can also increase due to distention of intervillous space. Placental thickness depends on amount of fetal blood, maternal blood and placental tissue. Correct identification of placental myometrial interface is important for proper measurements of placenta. Placental thickness value, in $\mathrm{mm}$, was calculated by averaging the three best measurements for each case. Thus the placental thickness was measured trans-abdominally by using Toshiba or Samsung color Doppler scanner with a 3.5$\mathrm{MHz}$ convex transducer placing it perpendicularly to the plane of the placenta, in the area of the cord insertion at second and third trimester (18 - 40 weeks).

Placental thickness as obtained by ultrasonography and correlated with fetal parameters such as femur length (FL), biparietal diameter (BPD), head circumference (HC) and the abdominal circumference (AC) was used to predict estimated fetal birth weight (EFBW) as primary outcome. Secondary outcome measures include Birth weight, Apgar Score, NICU admission and Neonatal morbidity and mortality.

\section{Statistical analysis}

Statistical analysis was performed using the SPSS 16.0 statistical software package (SPSS). The data collected in this study was analysed statistically by computing the descriptive statistics viz., mean, SD, median, range and statistical significance was evaluated by student " $t$ " test or chi-square test. The correlation between placenta 
thickness and expected birth weight was computed. Pearson's correlation analysis was used to establish the degree of relationship between placental thickness and estimated fetal birth weight. ' $\mathrm{P}$ ' values of less than 0.05 were considered statistically significant.

\section{RESULTS}

The present study was conducted in the Department of Obstetrics and Gynaecology in collaboration with Department of Radiology and Department of Paediatrics, J.N. Medical College and Hospital, Aligarh, Uttar Pradesh, India. Total of 152 women were included in the study. The mean maternal age in our study was 25.21 \pm 4.67 . Maximum number of women were in the group range $20-24$ years i.e. $66(43.5 \%)$ while $3(1.9 \%)$ women were in the age group of $>35 y$ rs (Table 1 ).

Table 1: Maternal age distribution.

\begin{tabular}{|lll|}
\hline Age group (Years) & No. of cases & Percentage \\
\hline$<20$ & 06 & 03.9 \\
\hline $20-24$ & 66 & 43.5 \\
\hline $25-29$ & 53 & 34.9 \\
\hline $30-35$ & 24 & 15.8 \\
\hline$>35$ & 03 & 01.9 \\
\hline Total & 152 & 100.0 \\
\hline
\end{tabular}

The mean gestational age of women was 33.36 \pm 5.90 . Maximum numbers of women belong to gestational age group range of 36-40weeks while the minimum women were in the gestational age group of 21-25weeks (Table 2).

Table 2: Gestational age distribution.

\begin{tabular}{|ll|l|}
\hline Gestational age (weeks) & No. of cases & $\%$ \\
\hline$\leq 20$ & 12 & 07.8 \\
\hline $21-25$ & 10 & 06.6 \\
\hline $26-30$ & 13 & 08.6 \\
\hline $31-35$ & 52 & 34.2 \\
\hline $36-40$ & 65 & 42.8 \\
\hline Total & 152 & 100.0 \\
\hline
\end{tabular}

The mean placental thickness (Mean \pm SD) between the ranges of $18-40 \mathrm{~mm}$ was $31.63 \pm 4.79 \mathrm{~mm}$ and the mean estimated fetal birth weight was $2145.86 \pm 121.24$ grams.

The pearson's correlation coefficient between the two was 0.982 , proving the significant positive correlation between placental thickness and estimated fetal birth weight. Thus as the placental thickness increases, the estimated fetal birth weight increases ( $p$-value <0.001) (Table 3).

As shown in Table 4 there is high positive correlation between placental thickness and estimated fetal weight as correlation coefficient ' $r$ ' is 0.982 .

Table 3: Correlation of placental thickness with estimated fetal birth weight (EFBW).

\begin{tabular}{|lll|}
\begin{tabular}{|l} 
Gestational \\
age (weeks)
\end{tabular} & $\begin{array}{l}\text { Placental } \\
\text { thickness }(\mathrm{mm}) \\
\text { Mean } \pm \text { SD }\end{array}$ & $\begin{array}{l}\text { Estimated } \\
\text { fetal } \\
\text { Weight (gms) }\end{array}$ \\
\hline 18 & $18.5 \pm 0.7$ & $273.5 \pm 68.5$ \\
\hline 19 & $22.5 \pm 3.5$ & $233.00 \pm 36.7$ \\
\hline 20 & $21.6 \pm 1.7$ & $320.6 \pm 123.8$ \\
\hline 21 & $21.0 \pm 0.0$ & $421.0 \pm 0.0$ \\
\hline 22 & $27.0 \pm 0.0$ & $478.0 \pm 0.0$ \\
\hline 23 & $26.0 \pm 0.0$ & $643.0 \pm 0.0$ \\
\hline 24 & $25.2 \pm 0.9$ & $628.5 \pm 30.3$ \\
\hline 25 & $26.3 \pm 3.2$ & $612.0 \pm 270.2$ \\
\hline 26 & $26.6 \pm 1.1$ & $864.33 \pm 137.4$ \\
\hline 27 & $28.6 \pm 1.1$ & $1226.6 \pm 516.5$ \\
\hline 29 & $29.0 \pm 1.72730$ & $1311.0 \pm 87.7$ \\
\hline 30 & $29.7 \pm 0.5$ & $1434.25 \pm 309.3$ \\
\hline 32 & $30.7 \pm 3.0$ & $1772.7 \pm 389.1$ \\
\hline 33 & $32.7 \pm 2.3$ & $2108.0 \pm 441.2$ \\
\hline 34 & $31.6 \pm 3.4$ & $2223.90 \pm 385.3$ \\
\hline 35 & $33.6 \pm 2.6$ & $2506.90 \pm 375.2$ \\
\hline 36 & $34.1 \pm 2.5$ & $2428.0 \pm 402.9$ \\
\hline 37 & $35.1 \pm 2.9$ & $2977.92 \pm 648.8$ \\
\hline 38 & $33.2 \pm 2.4$ & $2730.93 \pm 534.3$ \\
\hline 39 & $34.4 \pm 3.4$ & $2949.4 \pm 201.9$ \\
\hline 40 & $34.0 \pm 3.0$ & $3045.1 \pm 320.3$ \\
\hline
\end{tabular}

Table 4: Correlation of placental thickness with estimated fetal birth weight (EFBW).

\begin{tabular}{|llllll|l|}
\hline & $\begin{array}{l}\text { Total } \\
\text { no. of cases (n) }\end{array}$ & Range & Mean & SD & P- & $\begin{array}{l}\text { Pearson } \\
\text { correlation }\end{array}$ \\
\hline PT (mm) & 152 & $18-40$ & 31.63 & 4.79 & $<0.001$ & 0.982 \\
\hline EFBW (gms) & 152 & $262-4012$ & 2145.86 & 121.24 & & \\
\hline
\end{tabular}

\section{DISCUSSION}

Placental thickness appears to be a promising parameter for estimation of weight of the fetus because of increase in placental thickness with advancing gestational age.
Sonographic measurements of fetal body parts provide a direct way of assessing fetal size. Numerous formulas have been published for estimating fetal weight from one or more of the following fetal body measurements: head (BPD, HC), abdomen (AC) and femur (FL). The 
accuracy of weight prediction formulas improves as the number of measured body parts increases up to three, achieving greatest accuracy when measurements of the head, abdomen and femur are used. In addition to the routine fetal biometry parameters, various studies were done trying to deduce a relationship between the placental thickness and estimated fetal weight. Our findings are in harmony with the study conducted by Baghel $P$ et al who observed significant positive correlation placental thickness with estimated fetal weight and birth weight. ${ }^{7}$ Estimated fetal weight increases with placental thickness $(\mathrm{r}=0.740$ and $\mathrm{p}=0.000)$. Adhikari $\mathrm{R}$ et al observed that the estimated fetal birth weight which is calculated based on a formula having FL, $\mathrm{BPD}$ and $\mathrm{AC}$ as variables is dependent on placental thickness which is similar to our observations. ${ }^{8}$ Afrakhteh $M$ et al observed a significant positive correlation between placental thickness and fetal weight in second and third trimester which is coherent with our study results. ${ }^{9}$

Placental thickness and estimated fetal birth weight have a significantly high positive correlation in both the trimesters as noted by Abu PO et al. ${ }^{10}$ The usefulness of this relationship between placental thickness and estimated festal weight is that subnormal placental thickness for a gestational age may be the earliest indicator of fetal growth retardation.In study of Kinare et al mid pregnancy placental volume was related to birth weight. ${ }^{11}$ Clapp et al evaluated placental growth of forty singleton pregnant women and showed a significant correlation $r>0.79$ between placental growth rate and birth weight. ${ }^{12}$

\section{CONCLUSION}

Estimated fetal weight is a very important component of antenatal care in which ultrasonography plays an important role. Placental thickness measured at the level of umblical cord insertion can be used as an accurate sonographic indicator in the assessment of because of its linear correlation. Therefore, it can be used as an additional sonographic tool in assessing fetal weight.

Funding: No funding sources

Conflict of interest: None declared

Ethical approval: The study was approved by the Institutional Ethics Committee

\section{REFERENCES}

1. Suri S, Muttukrishna S, Jauniaux E. 2D-ultrasound and endocrinologic evaluation of placentation in early pregnancy and its relationship to fetal birthweight in normal pregnancies and preeclampsia. Placenta. 2013;34(9):745-50.

2. Azpurua H, Funai EF, Coraluzzi LM, Doherty LF, Sasson IE, Kliman M, et al. Determination of placental weight using two- dimensional sonography and volumetric mathematic modeling. Am J Perinatol. 2010;27(2):151-5.

3. Salafia CM, Zhang J, Miller RK, Charles AK, Shrout P, Sun W.Placental growth patterns affect birth weight for given placental weight. Birth Defects Res Clin Mol Teratol. 2007;79(4):281-8

4. Hoddick WK, Mahony BS, Callen PW, Filly RA. Placental thickness. J Ultrasound Med 1985;4(9):479-82.

5. Pinette MG, Pan T, Blackstone J, Pinette SG. Ultrasound Placental thickness measurements and pregnancy outcomes. Am J Obstet Gynecol. 1998;178 (supp 1):S167

6. Dombrowski MP, Wolfie HM, Salch A, Evans Mt. O Brien J. The sonographically thick placenta: a predictor of increased perinatal morbidity and mortality. Ultrasound Obstet Gynecol. 1992;2:252-5.

7. Kaushal L, Patil A, Kocherla K. Evaluation of placental thickness as a sonological indicator for estimation of gestational age of fetus in normal singleton pregnancy. International J Res Med Sci. 2015;3(5):1213-8.

8. Adhikari R, Deka PK, Tayal A, Chettri PK. Ultrasonographic evaluation of placental thickness in normal singleton pregnancy for estimation of gestational age. Int J Med Imaging. 2015;3(6):143-7.

9. Afrakhteh M, Moini A, Sanei M, Raza $H$. Correlation between placental thickness in the second and third trimester and fetal weight. Rev bras Gynaecol Obstet. 2013;35(7):317-23.

10. Ohagwa CC, Abu PO, Ezeokeke UO,Ugwa AC. Placental thickness a sonographic indicator of gestational age. Internet J Med Update. 2009;4(2):914.

11. Kinare AS, Natekar AS, Chinchwadkar MC, Yanik $\mathrm{CS}$, Fall $\mathrm{CH}$ et al. Low midpregnancy placental volume in rural Indian women: a cause for low birth weight. Am Journal Obstet Gynecol. 2000;182(2):443-8.

12. Clapp JF 3rd, Rizk KH, Appleby-Wineberg SK, Crass JR. Second- trimester placental volumes predicts birth weight at term. J Soc Gynecol Investig. 1995;2(1):19-22.

Cite this article as: Noor N, Jain A, Parveen S, Ali SM. Ultrasonographic measurement of placental thickness and its correlation with estimated fetal weight. Int J Reprod Contracept Obstet Gynecol 2018;7:287-90. 